Research Paper:

\title{
Evaluation of the Patient Safety Culture Status and its Related Factors From the Perspective of Operating Room Personnel
}

\author{
Ehsan Memarbashi' ${ }^{1}$ (D), Omid Zadi Akhuleh ${ }^{1}$ (D), Fatemeh Imani' ${ }^{1}$ (D) Ebrahim Nasiri $^{\text {* }}$ (D)
}

1. Department of Anesthesiology and Operating Room, Faculty of Allied Medical Sciences, Medical Student Research Committee, Mazandaran University of Medical Sciences, Sari, Iran.

2. Department of Anesthesiology and Operating Room, Faculty of Allied Medical Sciences, Traditional and Complementary Medicine Research Center, Addiction Institute, Mazandaran University of Medical Sciences, Sari, Iran.

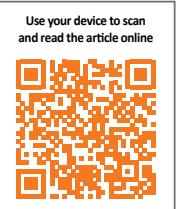

ditation: Memarbashi, E., et al., 2020. Evaluation of the Patient Safety Culture Status and its Related Factors From the Perspective of Operating Room Personnel. Journal of Client-Centered Nursing Care, 6(1), pp. 23-30. https://doi.org/10.32598/ JCCNC.6.1.307.1

https://doi.org/10.32598/JCCNC.6.1.307.1

Keywords:

Patient safety, Safety culture, Operating room

\section{A B S T RA C T}

Background: Patient safety is one of the principles of health care and evaluation of the patient safety culture motivates to provide safe conditions for patient care. Regarding the invasive procedures and the necessity of special attention to patient safety in the operating room, this study aimed to determine the patient safety culture from the perspective of operating room personnel.

Methods: This research was a descriptive cross-sectional study. The study sample consisted of 206 operating room personnel of Mazandaran educational hospitals who were selected by stratified random sampling. Data collection was performed using the patient safety culture questionnaire and a demographic form. The obtained data were analyzed by descriptive and inferential statistics (Pearson correlation test, one-way ANOVA, independent t-test, and Chisquare test) in SPSS V. 20. The significance level was set at less than 0.05 .

Results: Most of the operating room personnel (72.3\%) rated the patient safety culture as moderate. Among the dimensions of patient safety culture, "non-punitive response to error" was not favorable (7.4 \pm 2$)$ and the dimensions of the "frequency of error reporting" (11.5 \pm 2.2$)$, "overall perceptions of patient safety" $(15.1 \pm 2.4)$, and "teamwork within units" $(15.4 \pm 2.9)$ were rated as favorable. Among the studied variables, there was a significant relationship between occupational groups and safety culture $(\mathrm{P}=0.04)$.

Conclusion: Patient safety culture status was moderate from the perspective of most operating room personnel. Considering the greater sensitivity of safety in the operating room, hospital managers should adopt suitable approaches and policies to promote the patient safety culture.

\section{* Corresponding Author:}

Ebrahim Nasiri, PhD.

Address: Department of Anesthesiology and Operating Room, Faculty of Allied Medical Sciences, Traditional and Complementary Medicine Research Center Addiction Institute, Mazandaran University of Medical Sciences, Sari, Iran.

Tel: +98 (911) 1517836

E-mail: rezanf2002@yahoo.com 


\section{Highlights}

- Patient safety is considered as an inherent component of healthcare quality.

- The main requirement to improve patient safety is to promote patient safety culture.

- Nowadays despite the significant progress of medical science, there are still a lot of unintended harms that threaten patients all around the world.

- The nature of the operating room requires a different approach to patient safety, as various invasive procedures are performed in this room.

\section{Plain Language Summary}

Unsafe culture of healthcare employees is a major issue for healthcare providers in promoting the quality of care which is closely correlated with the occurrence of hospital errors and incidents. The operating room is one of the main units in the hospital, where the most important phase of patient treatment is performed. This study was designed to determine the status of patient safety culture and its related factors from the perspective of operating room personnel. According to the results, the average safety culture was not ideal in the operating room personnel.

\section{Introduction}

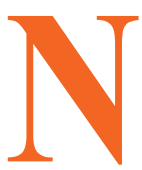

owadays one of the human concerns in the field of health care is the maintenance of patient safety in medical centers. But despite the efforts of many health care organizations, huge errors still happen with significant financial and human costs (Psaty \& Burke 2006). Patient safety from the perspective of the World Health Organization is avoidance and removal of unexpected or potentially health-relevant damages (Emami Razavi et al., 2011).

Using approaches to improve patient safety is one of the key practices that have been the focus of health care organizations in the early $21^{\text {st }}$ century. Improving patient safety is a common international priority, as many errors are currently occurring worldwide in the care and treatment of patients (Milligan 2007; Matsubara, Hagihara $\&$ Nobutom 2008). Some of these errors are medication errors (errors in the type or dose of the drug), surgeries (surgery on an incorrect part, using the wrong technique, postoperative complications), inappropriate diagnoses (delay in diagnosis, non-diagnosis, incorrect diagnosis), nosocomial infections, patient falls, bedsores, and incorrect treatment (Abdi, Maleki \& Khosravi 2012). In developed countries, $10 \%$ of patients receiving health care, encounter medical errors, while this is much higher in developing countries (Izadi, Jahangir \& Ebrazeh 2013).
A study in Canada found that between $7.5 \%$ and $12.7 \%$ of hospitalized patients have been exposed to medical errors (Baker et al., 2004). There is no record of medical errors in Iran, but the Ministry of Health and Medical Education has reported that millions of dollars are spent each year on patient care in hospitals due to medical errors (Niknejad et al., 2019). Health care organizations have been working to promote and improve the quality of services and paying increasing attention to patient safety (Mousavi et al., 2017). One of the most widely regarded aspects of patient safety is its culture (Bodur \& Filiz 2010; Chen \& Li 2010). Various studies have reported that the most important obstacle on the way of improving patient safety is the safety culture of health care organizations and have stated that constructive safety culture is the key to patient safety improvement (Castle \& Sonon 2006; Zwart et al., 2011). Therefore, to improve patient safety in such centers, it is necessary to maintain a robust patient safety culture among personnel along with structural interventions (Smits et al., 2008). In other words, in healthcare organizations, improving the patient safety culture and transitioning from a culture that believes no error or harm will be changed to a culture that encourages reporting-even reporting errors in which the patient has not been injured-can play an important role in preventing errors and improving service quality (Wilson 2007).

Evaluation of the safety culture of organizations leads to a brighter view of those dimensions of patient safety that need more attention and allows hospitals to identify the strengths and weaknesses of their safety culture 
and patient safety issues (El-Jardali et al., 2010). Mahfooz pour et al. considered as moderate level the status of patient safety culture in training hospitals affiliated to Shahid Beheshti University of Medical Sciences (Mahfoozpour et al., 2012). Also, Abdi in his study reported the status of cultural dimensions of patient safety as undesirable (Abdi, Maleki \& Khosravi 2012). One of the hospital departments which is recognized according to its organizational, educational, environmental and technological needs as the most high-risk areas of a health center is the operating room ward (Christian et al., 2006).

Statistics have shown that most accidents and injuries occur in the operating room and emergency departments; thus it is necessary to pay more attention to the reduction of the risk of medical errors in such places (Khalooei, Mehdipour, Rabori \& Nakhaee 2013). Thus the importance of patient safety in the operating room and the key role of operating room personnel in maintaining patient safety and adverse consequences of inattention to patient safety is clear. However, studies on safety culture status in operating room wards are very limited. Therefore, this study was carried out to determine the status of patient safety culture and its related factors in operating rooms from the perspective of its personnel.

\section{Materials and Methods}

This research is a descriptive cross-sectional study to determine the status of patient safety culture and its related factors from the perspective of operating room personnel of the Hospitals affiliated with Mazandaran University of Medical Sciences (Imam Khomeini, Fatemeh Zahra, Zare, Bu Ali Sina \& Razi). The study population consisted of operating room personnel (surgical technologists and anesthesia technicians). The study was carried out for 6 months from February to July 2019. Giving informed consent, and having at least 6 months of experience in the operating room were the inclusion criteria and those who did not have the consent to participate in the study were excluded.

A total of 206 subjects were selected using a stratified random sampling method. Each of the 5 selected hospitals in this study was considered as a stratum and the samples were selected randomly according to the number of subjects in each stratum. Data were collected using the hospital survey on patient safety culture questionnaire. This questionnaire was designed by the US Agency for Health Care Quality Research in 2004 (Almasi et al., 2015) and contains 42 items which evaluate staff perceptions of the patient safety culture in 12 dimensions (frequency of error reporting, overall perceptions of patient safety, supervisor/manager expectations and actions promoting safety, organizational learning-continuous improvement, teamwork within units, communication openness, feedback and communication about the error, non-punitive response to error, staffing, hospital management support for patient safety, teamwork across hospital units, and hospital handoffs and transitions) on a 5-point Likert scale from "completely disagree" to "strongly agree". Each of the areas of the frequency of error reporting, organizational learning-continuous improvement, communication openness, feedback and communication about the error, non-punitive response to error, and hospital management support for patient safety has three questions and scores between 3 and 15 . Weak level refers to scores less than 7.5; moderate level to scores from7.5 to less than 11.25, and favorable level to scores more than 11.25. Each of the areas of overall perceptions of patient safety, supervisor/manager expectations and actions promoting safety, teamwork within units, staffing, teamwork across hospital units, and hospital handoffs and transitions has 4 questions and scores from 4 to 20 . Weak level refers to scores less than 10; moderate level to scores from 10 to less than 15, and favorable level to scores more than 15 . Total patient safety culture scores ranges from 42 to 210 (weak level=scores less than 98 , moderate level $=99$ to 154 , and favorable level=above 155). The validity and reliability of the Persian version of this questionnaire have been confirmed in Iran (Moghri et al. 2012). In the present study, the reliability of the questionnaire was evaluated again using the Cronbach alpha coefficient which was 0.81 .

The questionnaires were distributed among the participants without mentioning the name in the study and the participants were assured of the confidentiality of their information. The obtained data entered into SPSS V. 20 and were analyzed using descriptive statistics, the Pearson correlation test, One-way ANOVA, independent ttest, and Chi-square test.

\section{Results}

A total of 206 personnel of the operating rooms of the educational hospitals of Mazandaran University of Medical Sciences participated in the study. The results showed that most of the participants were female $(55.3 \%)$, married $(81.1 \%)$, officially employed $(37.9 \%)$, and with a bachelor's degree $(78.2 \%)$. The Mean \pm SD age of the participants was $33.4 \pm 6.9$ years and their experience in the operating room was $10 \pm 7.1$ years. Other demographic characteristics are presented in Table 1.

The Mean \pm SD score of the total patient safety culture of the participants was $143.9 \pm 18.2$, which is classified as moderate (99-154). Table 2 presents the relationship between the safety culture score and the studied variables. Among 
Table 1. Frequency distribution of the participants according to demographic characteristics

\begin{tabular}{|c|c|c|}
\hline Characteristics & Variables & No. (\%) \\
\hline \multirow[b]{2}{*}{ Occupational groups } & Surgical technologist & $110(53.4)$ \\
\hline & Anesthesia technician & 96 (46.6) \\
\hline \multirow{2}{*}{ Gender } & Male & $92(44.7)$ \\
\hline & Female & $114(55.3)$ \\
\hline \multirow{2}{*}{ Marital status } & Single & 39 (18.9) \\
\hline & Married & $167(81.1)$ \\
\hline \multirow{3}{*}{ Education level } & Associate degree & $36(17.5)$ \\
\hline & BSc. degree & $161(78.2)$ \\
\hline & MSc. degree & $9(4.4)$ \\
\hline \multirow{4}{*}{ Employment Status } & Official & 78 (37.9) \\
\hline & Contractual & 60 (29.1) \\
\hline & Bespoke & $32(15.5)$ \\
\hline & Project & $36(17.5)$ \\
\hline
\end{tabular}

Client- Centered Nursing Care

the variables, there was a significant relationship between occupational groups and safety culture $(\mathrm{P}=0.04)$, so that the safety culture scores in anesthesia personnel were more than surgical technologists. Based on the findings of Table 2 , the mean score of safety culture according to the employ- ment status of the participants showed a significant difference $(\mathrm{P}=0.01)$, so that the employees with official employment had the highest score on safety culture (Table 2 ).

Table 2. Relationship between safety culture and study variables

\begin{tabular}{cccc}
\hline \multicolumn{2}{c}{ Variables } & Mean \pm SD & P \\
\hline \multirow{2}{*}{ Occupational groups } & Surgical technologist & $141.5 \pm 17.5$ & 0.04 \\
& Anesthesia technician & $146.6 \pm 18.7$ & 0.64 \\
Gender & Male & $142.2 \pm 16.8$ & 0.40 \\
Marital status & Female & $143.8 \pm 16.3$ & \\
& Single & $141.7 \pm 16.1$ & \\
& Married & $144.7 \pm 18.7$ & 0.019 \\
\hline & Official & $148.3 \pm 21.1$ & $141.6 \pm 13.3$ \\
& Contractual & $137.3 \pm 19$ & $143.8 \pm 16$ \\
\hline
\end{tabular}


Table 3. Frequency distribution of the level of safety culture from the participants' perspective

\begin{tabular}{cc}
\hline PSCLevel * & No. (\%) \\
\hline Weak (42-98) & $3(1.5)$ \\
Moderate (99-154) & $149(72.3)$ \\
Favorable (155-210) & $54(26.2)$ \\
* Total & 206 (100) \\
\hline
\end{tabular}

Table 4. Mean and level of patient safety culture dimensions from the perspective of operating room staff

\begin{tabular}{|c|c|c|c|c|}
\hline \multirow{2}{*}{ Dimensions } & & \multirow{2}{*}{ Surgical-Technologists } & \multirow{2}{*}{ Anesthetists } & \multirow{2}{*}{$\mathbf{P}$} \\
\hline & Level & & & \\
\hline Frequency of error reporting & $\begin{array}{l}11.5 \pm 2.2 \\
\text { Favorable }\end{array}$ & $11.3 \pm 2.2$ & $11.6 \pm 2.2$ & 0.349 \\
\hline Overall perceptions of patient safety & $\begin{array}{l}15.1 \pm 2.4 \\
\text { Favorable }\end{array}$ & $14.8 \pm 2.5$ & $115.4 \pm 2.3$ & 0.067 \\
\hline $\begin{array}{l}\text { Supervisor/manager expectations and } \\
\text { actions promoting safety }\end{array}$ & $\begin{array}{l}14.5 \pm 3.1 \\
\text { Moderate }\end{array}$ & $14.2 \pm 3$ & $14.8 \pm 3.2$ & 0.157 \\
\hline $\begin{array}{l}\text { Organizational learning-continuous } \\
\text { improvement }\end{array}$ & $\begin{array}{l}10.9 \pm 2.1 \\
\text { Moderate }\end{array}$ & $10.6 \pm 2$ & $11.2 \pm 2.2$ & 0.063 \\
\hline Teamwork within units & $\begin{array}{l}15.4 \pm 2.9 \\
\text { Favorable }\end{array}$ & $15.2 \pm 2.9$ & $15.6 \pm 2.8$ & 0.281 \\
\hline Communication openness & $\begin{array}{c}9.4 \pm 2.1 \\
\text { Moderate }\end{array}$ & $9.2 \pm 2.2$ & $9.6 \pm 2$ & 0.205 \\
\hline $\begin{array}{l}\text { Feedback and communication about } \\
\text { error }\end{array}$ & $\begin{array}{l}10.6 \pm 2.1 \\
\text { Moderate }\end{array}$ & $10.4 \pm 2$ & $10.7 \pm 2.3$ & 0.266 \\
\hline Non-punitive response to error & $\begin{array}{l}7.4 \pm 2 \\
\text { Weak }\end{array}$ & $7.2 \pm 2$ & $7.7 \pm 2.1$ & 0.138 \\
\hline Staffing & $\begin{array}{c}11.2 \pm 2.6 \\
\text { Moderate }\end{array}$ & $11.2 \pm 2.7$ & $11.3 \pm 2.6$ & 0.951 \\
\hline $\begin{array}{l}\text { Hospital management support for } \\
\text { patient safety }\end{array}$ & $\begin{array}{l}10.2 \pm 2.7 \\
\text { Moderate }\end{array}$ & $9.9 \pm 2.7$ & $10.7 \pm 2.7$ & 0.047 \\
\hline Teamwork across hospital units & $\begin{array}{c}9.9 \pm 2.2 \\
\text { Moderate }\end{array}$ & $9.7 \pm 2.1$ & $10.2 \pm 2.7$ & 0.119 \\
\hline Hospital handoffs and transitions & $\begin{array}{l}17.6 \pm 3.3 \\
\text { Moderate }\end{array}$ & $17.5 \pm 3.4$ & $17.8 \pm 3.3$ & 0.605 \\
\hline
\end{tabular}

Client- Centered Nursing Care

The findings indicated that participants' work experience had a significant influence on the safety culture $(r=0.346$, $\mathrm{P}=0.001$ ). It means that by increasing work experience, perception of safety culture also improves.
The results showed that most of the operating room personnel $(72.3 \%)$ participating in this study rated the level of patient safety culture as moderate (Table 3 ).

According to Table 4, a significant difference exists between surgical technologists and anesthesia personnel only in the area of "hospital management support for patient 
safety" ( $\mathrm{P}=0.047)$. Table 4 presents the participants' perceptions of the status of each dimension of patient safety culture at three levels of favorable, moderate, and weak.

\section{Discussion}

The results of this study showed that the level of patient safety culture was moderate from the perspective of operating room personnel. It was also shown that among the 12 dimensions of patient safety culture, "frequency of error reporting", "overall perceptions of patient safety", and "teamwork within units" were favorable. The results of a study in Turkey (Bodur \& Filiz 2010) showed that the "frequency of error reporting" among the other dimensions had the lowest mean, which is inconsistent with the findings of the present study. Another study evaluated the "frequency of error reporting" status as unsuitable and weak, which is also inconsistent with the present study (Mohebi Far et al., 2015). Error reporting is considered as one of the indicators of patient safety and it can reduce serious consequences at both practical and ethical levels and using information obtained from error reporting can help in managing existing errors and preventing future mistakes (Koohestani \& Baghcheghi 2009).

El-Jardali in his study evaluated the highest score of safety culture in the two dimensions of "teamwork within the units" and "organizational learning-continuous improvement", which is consistent with our study in the first dimension (El-Jardali et al., 2010). Some researchers mentioned "teamwork within the units" as a strength of the safety culture which is in line with our study (Abdi, Maleki \& Khosravi 2012; Salavati et al., 2013; Ebadi Fard azar et al., 2011). Functional results of teamwork include reducing the duration of hospitalization, decreasing the likelihood of patient readmission, increasing the power of communication and collaboration between physicians and other personnel, and also reducing the incidence of medical errors. Achieving patient safety depends on teamwork (Buljac-Samardzic et al., 2020). In the present study, "non-punitive response to error" was introduced as the main weakness of safety culture in operating room wards. This dimension has also been reported in the lowest levels of safety culture in other studies (Rockville et al., 2014; Bodur \& Filiz 2010; Ravaghi et al., 2012; Tabrizchi \& Sedaghat 2012; Yaghoobifar et al., 2012). Punishment and blame for errors will cause concealment, non-sharing errors, and failure to learn from the mistakes that occur and the probable occurrence of more errors. The American Medical Association has recommended that organizations should discard this culture that errors and mistakes arise from personal incompetence and consider the errors as opportunities for learning (El-Jardali et al., 2010).
In the present study, the work experience of the participants had a significant impact on the perception of safety culture. In other words, with more work experience, the safety culture score also increases. This finding is consistent with the results of some studies (Agharahimi et al., 2012; Mahfoozpour et al., 2012). However, the results of some other studies indicated that with increasing work experience, safety culture decreases, which is inconsistent with the results of our study (Moghri et al., 2012; Izadi, Jahangir \& Ebrazeh 2013). In the present study, there was a significant relationship between the score of patient safety culture from the perspective of the specialties, which was consistent with some other studies (Saber et al., 2015; Jahangiri et al., 2017). The difference between the results of other studies and ours may be due to the differences between operating room features, operating room workloads, and specialized structures of various sections. According to the results of this study, the score of patient safety culture in anesthesia technicians was higher than that of the surgical technologists. As a result, it seems that surgical technologists need more interventions to improve patient safety programs.

The limitation of this study was collecting information through self-administered questionnaires which increase subjectivity and bias in data collection.

This study revealed that patient safety culture status did not seem to be favorable from the perspective of operating room personnel. Patient safety is more sensitive in the operating room due to the nature of working in such units. Therefore, changing and enhancing the safety culture of all operating rooms is the most important issue that should be considered. Measures such as educational need assessment and using it for conducting courses and workshops and re-training in the field of patient safety and improving the motivation system (encouragement and punishment) are suggested for promoting the perception of operating room personnel of its safety culture.

\section{Ethical Considerations}

\section{Compliance with ethical guidelines}

This study was approved by the Ethical Research Committee of Mazandaran University of Medical Sciences (IR. MAZUMS.REC.1398.372). Informed consent was received from all participants. The data were collected anonymously and the participants were assured of the confidentiality of their information. 


\section{Funding}

This research project was supported by the Vice Chancellor of Research Department of Mazandaran University of Medical Sciences.

\section{Authors' contributions}

Analyzing data, drafting the manuscript, study design: Omid Zadi Akhuleh, Ehsan Memarbashi; Collecting data: Omid Zadi Akhuleh, Ehsan Memarbashi, Fatemeh Imani; : Supervision: All authors.

\section{Conflict of interest}

The authors declared no conflicts of interest.

\section{Acknowledgments}

The authors are grateful to the Deputy of Research and Technology of Mazandaran University of Medical Sciences. Our sincere gratitude is also dedicated to the Operating Rooms Staff for their assistance and cooperation.

\section{References}

Abdi, Z., Maleki, M. R., \& Khosravi, A., 2012. [Perceptions of patient safety culture among staff of selected hospitals affiliated to tehran university of medical sciences (Persian)]. Payesh, 10(4), pp. 411-9. https:/ / www.sid.ir/en/journal/ViewPaper.aspx?id=209269

Agharahimi, Z., et al., 2012. [Evaluation of staff attitudes about patients' safety culture in Noor \& Ali Asghar hospitals in Isfahan-2011 (Persian)]. Journal of Hospital, 11(3), pp. 17-26. http:// jhosp.tums.ac.ir/article-1-18-en.html

Almasi, A., et al., 2015. [Evaluation of patient safety culture in personnel of hospitals in Kermanshah, 2013 (Persian)]. Journal of Clinical Research in Paramedical Sciences, 4(1), pp. 14-23. https:// www.sid.ir/en/journal/ViewPaper.aspx?id=497289

Baker, G. R., et al., 2004. The Canadian adverse event study: The incidence of adverse event among hospital patients in Canada. Canadian Medical Association Journal, 170(11), pp. 1678-86. [DOI:10.1503/cmaj.1040498] [PMID] [PMCID]

Bodur, S., \& Filiz, E., 2010. Validity and reliability of Turkish version of "Hospital Survey on Patient Safety Culture" and perception of patient safety in public hospitals in Turkey. BMC Health Services Research, 10, p. 28. [DOI:10.1186/1472-6963-10-28] [PMID] [PMCID]

Buljac-Samardzic, M., Doekhie, K. D., \& van Wijngaarden, J. D. H., 2020. Interventions to improve team effectiveness within health care: Asystematic review of the past decade. Human Resource Health, 18, p. 2. https:// doi.org/10.1186/s12960-019-0411-3
Castle, N. G., \& Sonon, K. E., 2006. A culture of patient safety in nursing homes. Quality and Safety in Health Care, 15(6), pp. 405-8 [DOI:10.1136/qshc.2006.018424] [PMID] [PMCID]

Chen, I. C., \& Li, H. H., 2010. Measuring patient safety culture in Taiwan using the Hospital Survey on Patient Safety Culture (HSOPSC). BMC Health Services Research, 10, p. 152. [DOI:10.1186/14726963-10-152] [PMID] [PMCID]

Christian, C. K., et al., 2006. A prospective study of patient safety in the operating room. Surgery, 139(2), pp. 159-73. [DOI:10.1016/j. surg.2005.07.037] [PMID]

Ebadi Fard Azar, F., et al., 2011. [Study of patients' safety culture in Selected Training hospitals affiliated with Tehran university of medical sciences (Persian)]. Journal of Hospital, 11(2), pp. 55-64 http://jhosp.tums.ac.ir/article-1-28-en.html

El-Jardali, F., et al., 2010. The current state of patient safety culture in Lebanese hospitals: A study at baseline. International Journal for Quality in Health Care, 22(5), pp. 386-95. [DOI:10.1093/intqhc/ mzq047] [PMID]

Emami Razavi SH, R. H., et al., 2011. [Understanding the principles of clinical governance (Persian)]. Tehran: Tandis Publications.

Heidarpour, P., et al., 2011. [Presentation on theme clinical governance (Persian)]. Tehran: Tandis. http:/ /opac.nlai.ir/opac-prod/bibliographic/2400416

Izadi, A. R., Jahangir, D., \& Ebrazeh, A., 2013. [The patient safety culture in Fatemeh Zahra Hospital of Najafabad, Iran (Persian)] Health Information Management, 9(6), pp. 895-907. https:/ /www. sid.ir/en/journal/ViewPaper.aspx?id=402390

Jahangiri, M., et al., 2017. [Survey of patient safety culture in a Hospital in Shiraz, Iran, in 2015 (Persian)]. Journal of Health System Research, 13(2), pp. 146-50. https:/ / www.sid.ir/en/journal/ ViewPaper.aspx?id=566966

Khalooei, A., Mehdipour Rabori, M., \& Nakhaee N., 2013. [Safety condition in hospitals affiliated to Kerman University of Medical Sciences, 2010 (Persian)]. Health E Development Journal, 2(3), pp. 192-202. http:/ /jhad.kmu.ac.ir/article-1-41-en.html

Koohestani, H. R., \& Baghcheghi, N., 2009. Barriers to the reporting of medication administration errors among nursing students. Australian Journal of Advanced Nursing, 27(1), pp. 66-74. https:/ / www.ajan.com.au/archive/Vol27/Koohestani.pdf

Mahfoozpour, S., et al., 2012. [Patients' safety culture status among educational hospitals of Shahid Beheshti University of Medical Sciences (Persian)]. Pejoohandeh, 17(3), pp. 134-41. http://pajoohande.sbmu.ac.ir/article-1-1341-en.html

Matsubara, S., Hagihara, A., \& Nobutom, K., 2008. Development of a patient safety climate scale in Japan. International Journal for Quality in Health Care, 20(3), pp. 211-20. [DOI:10.1093/intqhe/ mzn003] [PMID]

Milligan, F. J., 2007. Establishing a culture for patient safety - The role of education. Nurse Education Today, 27(2), pp. 95-102. [DOI:10.1016/j.nedt.2006.03.003] [PMID]

Moghri, J., et al., 2012. Validation of Farsi version of hospital survey on patient Safety culture questionnaire, using confirmatory factor analysis method. Journal of Hospital, 11(2): pp. 19-30. http:/ /jhosp. tums.ac.ir/article-1-26-en.html

Mohebi Far, R., et al., 2015. [Studying patient safety culture from the viewpoint of staffs in educational hospitals in Tehran City (Per- 
sian)]. Journal of Health and Safety at Work, 5(1), pp. 57-64. http:/ / jhsw.tums.ac.ir/article-1-5243-en.html

Mousavi, S. M., et al., 2017. Observing patients' rights and the facilitating and deterrent organizational factors from the viewpoint of nurses working in intensive care units. Journal of Client-Centered Nursing Care, 3(1), pp. 27-36. [DOI:10.32598/jccnc.3.1.27]

Niknejad R., et al., 2019. [Attitudes of healthcare professionals toward patient safety in the operating room (Persian)]. Iran Journal of Nursing, 32(117), pp. 80-90. [DOI:10.29252/ijn.32.117.80]

Psaty, B. M., \& Burke, S. P., 2006. Protecting the health of the public-Institute of Medicine recommendations on drug safety. The New England Journal of Medicine, 355(17), pp. 1753-5. [DOI:10.1056/ NEJMp068228] [PMID]

Ravaghi, H., et al., 2012. [The relationship between health care providers' perceptions of patient safety culture and patients' perceptions of medical errors in teaching hospitals in Tehran (Persian)]. Journal of Health Administration, 15(48), pp. 57-68. http://jha.iums. ac.ir/article-1-965-en.html

Westat, R., et al., 2020. Hospital survey on patient safety culture: 2010 user comparative database report. An official website of the Department of Health and Human Services. Cited 19 May, 2010 https:// psnet.ahrq.gov/issue/hospital-survey-patient-safetyculture-2010-user-comparative-database-report

Sorra, J., et al., Hospital survey on patient safety culture: 2014 user comparative database report. Cited 2 August 2020, https:// psnet.ahrq gov/issue/hospital-survey-patient-safety-culture-2014-usercomparative-database-report

Saber, M., et al., 2015. [Acquaintance of Kerman hospitals' staff about patient safety culture (Persian)]. Health and Development Journal, 4(2), pp. 124-32. http://jhad.kmu.ac.ir/article-1-102-en. $\mathrm{html}$

Salavati, S., et al., 2013. [Nurses' perspectives on patient safety culture (Persian)]. Iran Journal of Nursing, 26(84), pp. 24-33. http:// ijn.iums.ac.ir/article-1-1628-en.html

Smits, M., et al., 2008. The psychometric properties of the "Hospital Survey on Patient Safety Culture "in Dutch hospitals". BMC Health Services Research, 8, p. 230. [DOI:10.1186/1472-6963-8-230] [PMID] [PMCID]

Tabrizchi, N., \& Sedaghat, M., 2012. The first study of patient safety culture in Iranian primary health centers. Acta Medica Iranica, 50(7), pp. 505-10. [PMID]

Wilson, K. A., 2007. Dose safety culture predict clinical outcome? [PhD. dissertation]. Florida: University of Central Florida.

Yaghoobifar, M. A., et al., 2012. [The survey of patient safety culture and recognizing its weaknesses and strengths in Sabzevar hospitals: 2011 (Persian)]. Journal of Sabzevar University of Medical Sciences, 20(2), pp. 154-64. http://jsums.medsab.ac.ir/article_325.html

Zwart, D. L. M., et al., 2011. Patient safety culture measurement in general practice. Clinimetric properties of' SCOPE. BMC Family Practice, 12, p. 117. [DOI:10.1186/1471-2296-12-117] [PMID] [PMCID] 